\title{
Prognostic Value of Plasma B-Type Natriuretic Peptide in the Long-Term Follow-up of Patients With Transposition of the Great Arteries With Morphologic Right Systemic Ventricle After Atrial Switch Operation
}

\author{
Stefanie Haberger, MD; Michael Hauser, MD, PhD; Siegmund L. Braun, MD; \\ Tibor Schuster, PhD; Peter Ewert, MD, PhD; Nicole Nagdyman, MD, PhD; \\ John Hess, MD, PhD; Harald Kaemmerer, MD, PhD
}

\begin{abstract}
Background: B-type natriuretic peptide (BNP) is an established marker for heart failure assessment, but the prognostic quality of BNP after atrial switch operation (ASO) has not yet been elucidated.

Methods and Results: In 89 patients (median age, 24 years; range, 15-35 years) after ASO, BNP was measured. During a 48-months follow-up we focused on critical cardiac events, defined as decompensation, sudden cardiac death or need for heart transplantation. BNP was considerably lower in 81 patients in functional class (FC) $1 / 1 \mathrm{l}$ (median, 35 pg/ml; range, 3-586 pg/ml) than in 6 patients in FC III/V (median, $246 \mathrm{pg} / \mathrm{ml}$; range, $14-1,150 \mathrm{pg} / \mathrm{ml}$, $P \leq 0.073)$. BNP was significantly higher after Mustard than after Senning procedure $(P \leq 0.030)$. There was no significant difference in BNP between simple or complex transposition of the great arteries (TGA) ( $P \leq 0.44)$. Eleven subjects (13\%, 95\% Cl: 7-22\%) had a critical cardiac event within 48 months. On ROC analysis BNP had a high predictive value regarding discrimination of patients with and without critical events (area under the ROC curve, 0.90; $95 \% \mathrm{Cl}: 0.76$ to $>0.99, \mathrm{P}<0.001$ ). The cut-off was $85 \mathrm{pg} / \mathrm{ml}$ (sensitivity, $88 \%$; specificity, $85 \%$ ). Additionally, estimated event-free-survival was longer after Senning than after Mustard procedure ( $P \leq 0.017)$. There was no significant difference in outcome between patients with simple or complex TGA with regard to occurrence of critical events.
\end{abstract}

Conclusions: BNP is a sensitive and specific prognostic marker for critical cardiac events after ASO. (Circ $J$ 2015; 79: 2677-2681)

Key Words: Atrial switch operation; B-type natriuretic peptide; Cardiac event; Congenital heart disease; Transposition of the great arteries

B -type natriuretic peptide (BNP), a cardiac hormone with diuretic, natriuretic, vasodilatory and anti-fibrotic properties, ${ }^{1,2}$ is a widely accepted marker in the assessment of left- and right ventricular function and heart failure. ${ }^{3} \mathrm{BNP}$ is mainly secreted by cardiac myocytes. ${ }^{4,5}$ The main stimuli for secretion are volume expansion or pressure load.

In patients with transposition of the great arteries (TGA) after atrial switch operation (ASO), the function of the morphologic right systemic ventricle is the main focus with regard to mid- and long-term morbidity and mortality. ${ }^{6-9}$

Recent studies support the hypothesis that natriuretic pep- tides play an important role in detecting ventricular dysfunction in patients with congenital heart disease (CHD) ${ }^{10-13}$ The role of BNP after ASO performed as Mustard or Senning procedure remains to be elucidated.

The objective of the present study was therefore to investigate the impact of BNP in the classification of heart failure after ASO and to evaluate whether BNP is an appropriate prognostic marker to identify patients at high risk for critical cardiac events, defined as decompensation, need for heart transplantation or sudden cardiac death.

Received April 5, 2015; accepted August 20, 2015; released online September 16, 2015 Time for primary review: 38 days

Department for Pediatric Cardiology and Congenital Heart Disease (S.H., M.H., P.E., N.N., J.H., H.K.), Institute of Laboratory Medicine (S.L.B.), German Heart Center, Munich; Institute for Medical Statistics and Epidemiology, Rechts der Isar Hospital, Technical University Munich, Munich (T.S.), Germany; and Department of Epidemiology, Biostatistics and Occupational Health, McGill University, Montreal (T.S.), Canada

The first two authors contributed equally to this work (S.H., M.H.).

Mailing address: Michael Hauser, MD, PhD, Department for Pediatric Cardiology and Congenital Heart Disease, German Heart Center,

Franz-Schrank Strasse 2, 80638 Munich, Germany. E-mail: hauser_kinderkardiologe@yahoo.de

ISSN-1346-9843 doi:10.1253/circj.CJ-15-0348

All rights are reserved to the Japanese Circulation Society. For permissions, please e-mail: cj@j-circ.or.jp 


\begin{tabular}{lc|}
\hline \multicolumn{2}{l}{ Table. Subject Clinical Characteristics } \\
\multicolumn{1}{c|}{ Variables } & $\mathbf{n = 8 9}$ \\
Age (years) & $24(15-35)$ \\
M/F & $53(60) / 36(40)$ \\
Surgery: Mustard/Senning operation & $45(51) / 44(49)$ \\
Age at surgery (years) & $1(0-17)$ \\
Functional class I,II/III,IV & $83(93) / 6(7)$ \\
\hline
\end{tabular}

Data given as median (range) or $\mathrm{n}(\%)$.

\section{Methods}

\section{Subjects}

Eighty-nine clinically stable patients (36 female, 53 male; median age, 24 years; range, 15-35 years) with TGA after ASO having their routine follow-up at the German Heart Centre Munich, were included in the study.

Venous puncture and assessment of plasma BNP were performed as part of the routine examination.

The medical records were reviewed for patient demographics and diagnosis. Patients were assigned to 4 functional classes (FC) according to the recommendations of Perloff et al; ${ }^{14}$ FC I, asymptomatic at all levels of activity; FC II, symptoms not curtailing average everyday activity; FC III, symptoms curtailing most but not all average everyday activity; FC IV, symptoms curtailing almost all average everyday activity and could be present at rest.

All patients received extensive information about the aim of the study. All patients or their legal guardians gave written informed consent. The study was approved by the ethics board of the medical faculty of the Technical University Munich.

\section{Assessment of Morbidity and Mortality}

Patients or their relatives were asked to fill in a questionnaire regarding physical wellbeing, physical capability and pharmacological treatment at the time of BNP assessment. In addition, information on cardiac decompensation with need for hospitalization, need for heart transplantation or cardiac death were collected.

\section{Sample Collection}

Venous samples were collected during routine assessment. All samples were collected into tubes containing potassium ethylenediamine tetra-acetic acid. BNP was measured within $8 \mathrm{~h}$ after collection using sandwich immunoassay (Triage BNP assay; Biosite Diagnostics, San Diego, CA, USA). Precision and sensitivity of this assay have been described elsewhere. ${ }^{15}$

\section{Statistical Analysis}

The study was conducted as a retrospective cohort study (ie, the study planning and data collection were performed after the actual study period), but the gathered data were prospective in nature, therefore conventional prospective methodological approaches such as Kaplan-Meier analysis and Cox proportional hazard regression were applicable. The cohort study design allowed for time-to-event analysis, comparing the event risks of subpopulations with different baseline attributes, in particular different BNP levels. Control for potential confounding factors was facilitated by including established outcome predictors in a multivariate Cox regression model.

The BNP assay is able to detect levels between 0 and $1,300 \mathrm{pg} / \mathrm{ml}$. Any level >1,300 was recorded as 1,300 for statistical evaluation. Due to a considerable lack of normality in distribution of BNP level, Mann-Whitney U-test was used to compare 2 patient groups with respect to this continuous endpoint, BNP level. Data are given as median, IQR, and range. Bivariate correlations between quantitative parameters and BNP level were evaluated using Spearman's correlation coefficient.

Receiver operating characteristics (ROC) analysis was carried out to investigate the diagnostic performance of BNP and to determine the most reliable cut-off in terms of correct prediction of any critical event (decompensation, heart transplantation or death). For the purpose of clinical significance, derivation of optimal BNP cut-off was restricted to a predefined lower level of sensitivity of $80 \%$ to be exceeded. The area under the ROC curve (AUC) is reported with 95\% CI to assess overall predictive performance of BNP.

Time-dependent event-free survival probabilities were estimated using the Kaplan-Meier method. Group comparisons regarding time to event data were performed using log-rank test and Cox proportional hazard models.

All statistical tests were 2-tailed and $\mathrm{P}<0.05$ was regarded as statistically significant. No multiplicity corrections of P-values or confidence levels were applied in the course of multiple testing. All analyses were conducted using SPSS for Windows Version 17.0 (SPSS, Chicago, IL, USA).

\section{Results}

A total of 89 patients with TGA after ASO (Mustard or Senning operation) were enrolled. The clinical characteristics are listed in Table.

All patients were in a stable clinical condition without signs of acute cardiac decompensation. Eighty-three patients were asymptomatic, or minimally symptomatic (FC I or II), and 6 had moderate to severe symptoms (FC III or IV). ${ }^{14}$

Patients in FC I or II were 1.5 years younger than patients with moderate to severe symptoms $(24 \pm 5$ years vs. $25.5 \pm 5$ years, $\mathrm{P}<0.54$ ).

Plasma BNP in all patients was assessed at clinical evaluation, and the median was $37 \mathrm{pg} / \mathrm{ml}$ (range, 3-1,150 pg/ml). A statistically significant positive correlation was seen between age and plasma $\mathrm{BNP}(\mathrm{r}= \pm 0.29 ; \mathrm{P}<0.032)$.

Plasma BNP was higher in female compared with male subjects, but the difference was not statistically significant (median, 50 vs. $26 \mathrm{pg} / \mathrm{ml} ; \mathrm{P}<0.069$ ).

Plasma BNP in FC I/II compared with that in the higher FC was not statistically significantly different (35 vs. $246 \mathrm{pg} / \mathrm{ml}$; $\mathrm{P} \leq 0.073$; Figure 1).

In patients with simple or complex TGA no significant difference in BNP was seen at evaluation, but BNP was significantly higher in patients after Mustard (median, $43 \mathrm{pg} / \mathrm{ml}$; IQR, $21-88 \mathrm{pg} / \mathrm{ml}$ ) than after Senning procedure (median, $27 \mathrm{pg} / \mathrm{ml}$; IQR, 13-54; P $\leq$ 0.030).

Patient clinical status was followed during a median of 19 months (range, 3-47 months) after BNP measurement. Eight of the 89 patients had 1 or more critical cardiac events (decompensation, heart transplantation or death) during follow-up: 7 patients developed cardiac decompensation, 3 underwent heart transplantation and 1 patient died (FC III at time of evaluation). ROC analysis for BNP regarding the prediction of at least 1 critical event showed an AUC of 0.90 (95\% CI: 0.76 to >0.99; $\mathrm{P}<0.001$; Figure 2).

A BNP-cut-off of $85 \mathrm{pg} / \mathrm{ml}$ was determined (sensitivity, $88 \%$; specificity, $85 \%$ ). Due to the low prevalence of critical events in the documented follow-up time this cut-off-level had a positive predictive value of only $37 \%$, but had a high negative predictive value of $99 \%$. Regarding event-free survival, there was a highly significant difference between patients with 


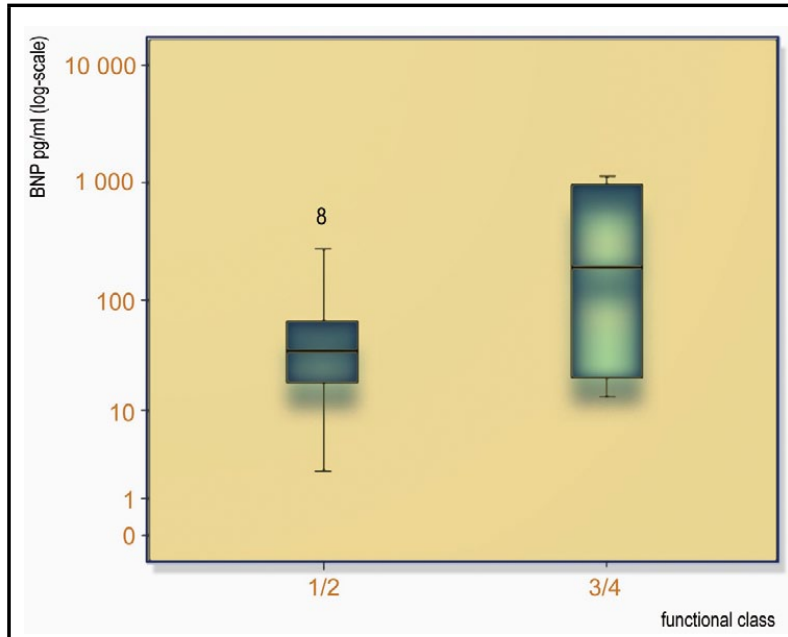

Figure 1. Plasma B-type natriuretic peptide (BNP) level according to functional class.

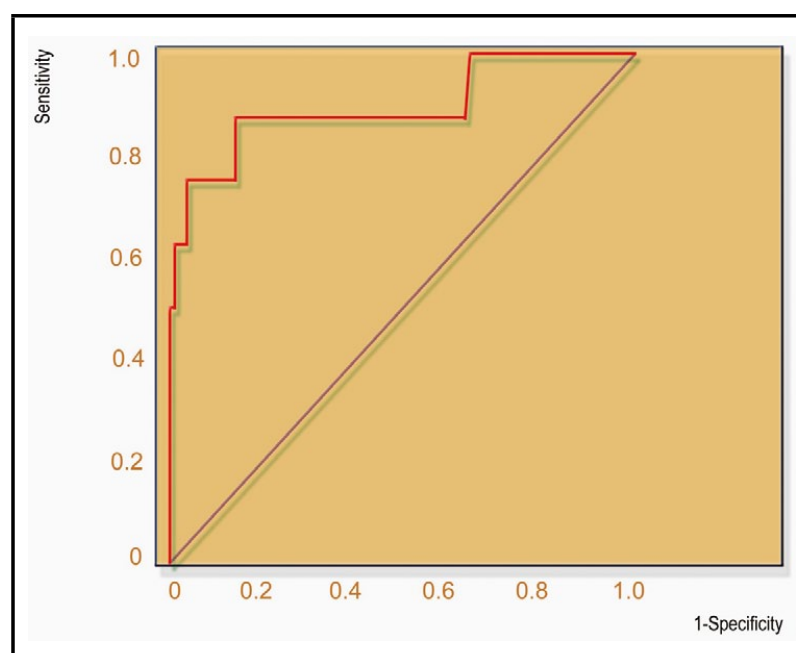

Figure 2. Receiver operating characteristic analysis of use of B-type natriuretic peptide level to identify patients at risk for critical events.

BNP below and above $85 \mathrm{pg} / \mathrm{ml}(\mathrm{P}<0.001)$. None of the patients with BNP below this cut-off had a critical event during follow-up, whereas the event-free survival in the group with BNP $>85 \mathrm{pg} / \mathrm{ml}$ was approximately $40 \%$ after 2 years (Figure 3).

Comparing patients after ASO for either simple or complex TGA, there was no statistically significant difference in event rates (log-rank test, $\mathrm{P} \leq 0.44$ ), and there was an almost equal distribution of critical events within the first 2.5 years of follow up, but a significantly higher risk for the occurrence of a critical event was observed for Mustard compared with Senning patients (log-rank test, $\mathrm{P} \leq 0.017$; HR, 8.48; $95 \% \mathrm{CI}$ : 1.04-69.2; Figure 4).

\section{Discussion}

In patients with TGA after ASO, failure of the morphologic right systemic ventricle is the main determinant of morbidity and mortality. ${ }^{16}$

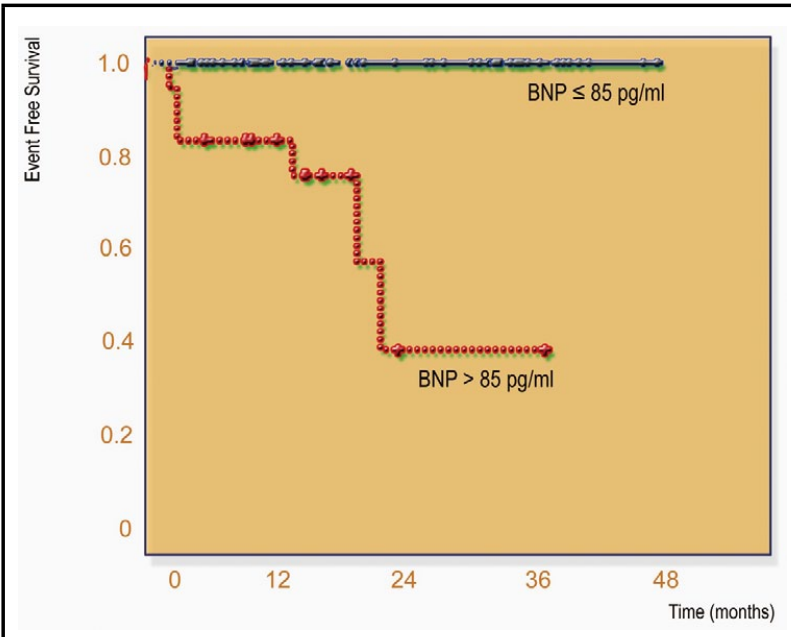

Figure 3. Event free survival according to plasma B-type natriuretic peptide (BNP) level.

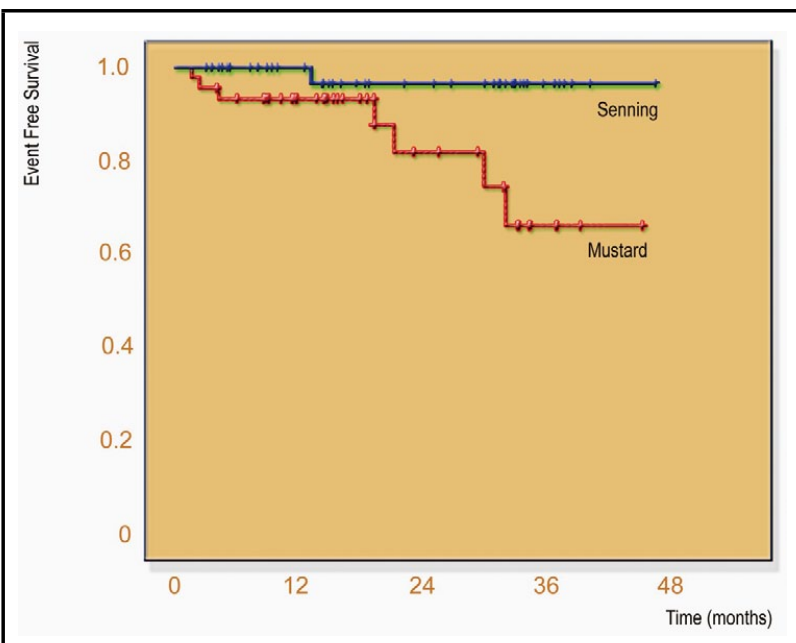

Figure 4. Event free survival according to operation type.

The etiology of this myocardial dysfunction is still hypothetical. Possible reasons include reduced preload in the case of baffle obstruction with inadequate ventricular filling, the atypical spheric shape and the structural morphology of the right ventricle with elevated end systolic and end diastolic volumes and an impairment of myocardial perfusion with reduced coronary flow reserve. ${ }^{17}$

In the clinical follow-up of these patients, a clinical parameter for estimating the appearance of cardiovascular complications and for risk stratification of cardiac events is needed.

The value of chest X-ray in detecting ventricular function is still controversial, and it has been suggested that less than half of the patients with ventricular dysfunction have a cardiothoracic ratio $>55 \% .{ }^{18}$ On comparison with other techniques there is a weak correlation between cardiothoracic ratio and radionuclide-, echocardiographic- and magnetic resonance imaging-derived volumes and ejection fraction. ${ }^{19}$ Electrocardiogram (ECG), chest X-ray and Holter-ECG findings were specifically not predictive of sudden cardiac death after 
Senning or Mustard repair. ${ }^{20}$

Heart rate is, according to the Frank-Starling mechanism, directly related to preload. In the case of baffle obstruction (reduced preload), which is not necessarily related to ventricular dysfunction, patients have an elevated heart rate compared with those without obstruction, therefore heart rate is a less favorable marker in detecting myocardial dysfunction. ${ }^{21}$ Additionally, after ASO many adult patients are treated with $\beta$-blockers or angiotensin-converting enzyme inhibitors; this medication has a significant influence on heart rate and blood pressure. Accordingly, blood pressure and heart rate vary widely according to the individual, and are not suitable for risk stratification of ventricular dysfunction.

In a previous study we noted a statistically significant negative correlation between BNP and coronary flow reserve, which is significantly attenuated in patients with dysfunction of the morphologic right systemic ventricle. ${ }^{21}$

$\mathrm{BNP}$ and N-terminal proBNP (NT-proBNP) are valuable biomarkers for the assessment of myocardial dysfunction..$^{22,23}$ Data on patients with systemic right ventricle, however, particularly adults after ASO for TGA, are scarce. ${ }^{22-26}$ The majority of studies describe these patients as a small subgroup of a heterogeneous collective.

To our knowledge this is one of the biggest studies to analyze BNP after ASO for TGA so far, demonstrating that BNP is, indeed, an important prognostic marker in this particular group of patients.

In the current study 89 patients after ASO were included. We chose to utilize BNP as marker substance because it might have a better correlation with a chronic clinical condition compared with NT-proBNP, which might be advantageous as a marker for more acute changes during the course of the disease. ${ }^{27,28}$ Few studies have directly compared the prognostic value of BNP and NT-proBNP in patients with heart disease. Some have concluded that these 2 markers are substantially equivalent, others have observed differences, particularly in acute settings: for instance in response to short-term exercise. $^{28}$

In the current study the 83 patients in FC I/II had a clearly lower plasma BNP level than the 6 patients in FC III or IV. In addition, there was a direct, but not significant, association between functional status and BNP. A similar association was described previously in adults with congestive heart failure from acquired heart disease, ${ }^{29,30}$ as well as in a general group of adults with $\mathrm{CHD}^{22}$ and, most recently, in patients with TGA. ${ }^{31,32}$ Moreover, the present data are also in agreement with the results from a smaller group of younger patients after ASO or with congenitally corrected TGA. In that study, asymptomatic patients had normal BNP, while BNP increased after deterioration of clinical status or with decreasing exercise capacity. ${ }^{33}$ In contrast, other groups did not find a relationship between BNP and exercise capacity after atrial redirection. ${ }^{34}$

Even more important than the association between BNP level and functional status is the relationship between plasma $\mathrm{BNP}$ and prognosis. The present data confirm the prognostic value of BNP after ASO. BNP has a high predictive value regarding critical cardiac events, defined as cardiac decompensation, need for heart transplantation or death, during follow-up. These data confirm the Koch et al results. ${ }^{33}$ Koch et al found a positive correlation between BNP and a regurgitant systemic atrioventricular valve, that is, the tricuspid valve in TGA after ASO, as well as a negative correlation with the exercise capacity and maximum $\dot{\mathrm{VO}}_{2}$ in these patients. Increasing atrioventricular valve regurgitation is of particular importance in this patient group because it is often combined with deterioration of systemic ventricular function. Additionally, others have found a positive correlation between BNP and quod vitam prognosis in pediatric heart failure. ${ }^{35-37}$

Interestingly there is no difference in outcome between patients with simple or complex TGA, but a significantly higher risk for a critical event was observed for Mustard compared with Senning patients.

In the present study group, at least $9 \%(n=8)$ had a critical cardiac event within 48 months. Seven patients developed cardiac decompensation, 3 had heart transplantation, and 1 had cardiac death. On ROC analysis, BNP had a high predictive value for discrimination of patients with and without critical events (AUC, 0.90; 95\% CI: 0.76 to $>0.99, \mathrm{P}<0.001$ ). The BNP cut-off was $85 \mathrm{pg} / \mathrm{ml}$ (sensitivity, $88 \%$; specificity, $85 \%$ ). Interestingly, the event-free survival after Senning procedure was longer than after Mustard procedure $(\mathrm{P}=0.017)$, matching the fact that BNP was significantly higher after Mustard procedure, but there were no differences between simple vs. complex TGA with regard to critical events.

This findings are in agreement with a study performed by Deanfield et al, which showed that late outcomes after the Senning procedure are superior to those after Mustard repair, largely because of the lower need for reoperation for venous pathway obstruction. ${ }^{38}$

The incidence of rhythm disturbances (atrial flutter) was lower in the group of patients after Senning repair, and diastolic function was impaired in the majority of patients after Mustard repair, because abnormal ventricular filling may be due, in part, to flow limitation by the atrial baffle..$^{39,40}$

In the present study the female patients had higher BNP, but the difference was not statistically significant. The data extend previous knowledge that BNP is significantly higher in women. These findings were not explained by age- or gender-related changes in blood pressure, renal function or cardiac structure. The association of female gender and BNP appears, in part, to be related to estrogen status, because BNP was higher in women using hormone replacement therapy. ${ }^{41,42}$

In conclusion, neurohormonal activation in adolescents and adults after ASO is an important indicator for the assessment of cardiac function. Moreover, BNP enables identification of patients at risk for critical cardiac events.

This is of critical importance because - in contrast to patients with acquired heart disease - patients with CHD often do not notice clinical deterioration in a timely manner.

Determination of BNP level allows the treating physician to assess the clinical situation, independently from subjective patient information. Moreover, the appearance of cardiovascular complications may be anticipated and treatment can be adjusted accordingly.

\section{Study Limitations}

The study was retrospective and the study group was relatively small, which limited the statistical power. There was a wide variety of patients with a different medical history; nevertheless, all patients had TGA after ASO (Senning/Mustard) with a morphologic right systemic ventricle; despite the different pre- and postoperative backgrounds, the function of this ventricle is the main determinant of long-term prognosis in these patients.

The present study was performed at a tertiary care center for adults with CHD. Thus, the present sample of patients does not represent the typical population of CHD seen by a general practitioner or cardiologist. The prevalence of more complex and severe cases in these institutions is likely to be higher than in community-based hospitals and departments for cardiology. 


\section{Disclosures}

None.

\section{References}

1. Levin ER, Gardner DG, Samson WK. Natriuretic peptides. $N$ Engl $J$ Med 1998; 339: 321-328.

2. Cowie MR, Mendez GF. BNP and congestive heart failure. Prog Cardiovasc Dis 2002; 44: 293-321.

3. Matsutani S, Saiki H, Kurishima C, Ishido H, Tamura M, Senzaki H. Heart failure with preserved ejection fraction in children: Hormonal imbalance between aldosterone and brain natriuretic peptide. Circ J 2013; 77: 2375-2382.

4. Kambayashi Y, Nakao K, Mukoyama M, Saito Y, Yamada T, Mukoyama $\mathrm{M}$, et al. Isolation and sequence determination of human brain natriuretic peptide in human atrium. FEBS Lett 1990; 259: 341-345.

5. LaPointe MC. Molecular regulation of the brain natriuretic peptide gene. Peptides 2005; 26: 944-956.

6. Davlouros PA, Niwa K, Webb G, Gazoulis MA. The right ventricle in congenital heart disease. Heart 2006; 92: $27-38$.

7. Dodge-Khatami A, Buechel EV, Knirsch W, Kadner A, Rousson V, Dave $\mathrm{HH}$, et al. Brain natriuretic peptide and magnetic resonance imaging in tetralogy with right ventricular dilatation. Ann Thorac Surg 2006; 82: 983-988.

8. Hoerer J, Herrmann F, Schreiber C, Cleuziou J, Prodan Z, Vogt M, et al. How well are patients doing up to 30 years after a mustard operation? Thorac Cardiovasc Surg 2007; 55: 359-364.

9. Hoerer J, Karl E, Theodoratou G, Schreiber C, Cleuziou J, Prodan Z, et al. Incidence and results of reoperations following the Senning operation: 27 years of follow-up in 314 patients at a single center. Eur J Cardiothorac Surg 2008; 33: 1061-1067.

10. Cantinotti M, Lorenzoni V, Storti S, Moschetti R, Murzi B, Marotta $\mathrm{M}$, et al. Thyroid and brain natriuretic peptide response in children undergoing cardiac surgery for congenital heart disease: Age related variations and prognostic value. Circ J 2013; 77: 188-197.

11. Koch A, Zink S, Singer H. B-type natriuretic peptide in paediatric patients with congenital heart disease. Eur Heart $J$ 2006; 27: $861-866$

12. Hirono K, Sekine M, Shiba N, Hayashi S, Nakaoka H, Ibuki K, et al. $\mathrm{N}$-terminal pro brain natriuretic peptide as a predictor of reoperation in children with surgically corrected tetralogy of Fallot. Circ J 2014; 78: $693-700$.

13. Garg R, Raman SV, Hoffman TM, Hayes J, Daniels CJ. Serum markers of systemic right ventricular function and exercise performance. Pediatr Cardiol 2008; 29: 641-648.

14. Perloff JK, Miner PD, Houser L. Specialized Facilities for Adults with Congenital Heart Disease. In: Perloff JK, Child JS, Aboulhosn J, editors. Congenital Heart Disease in Adults. 3rd ed. Philadelphia, USA: WB Saunders, 2008: 18-25.

15. Wieczorek SJ, Wu AH, Christenson R, Krishnaswamy P, Gottlieb S, Rosano T, et al. A rapid B-type natriuretic peptide assay accurately diagnoses left ventricular dysfunction and heart failure: A multicenter evaluation. Am Heart J 2002; 144: 834-839.

16. Lubiszewska B, Gosiewska E, Hoffman P, Teresinska A, Rozanski $\mathrm{J}$, Piotrowski W, et al. Myocardial perfusion and function of the systemic right ventricle in patients after atrial switch procedure for complete transposition: Long term follow up. J Am Coll Cardiol 2000; 36: 1365-1370.

17. Graham TP, Parrish MD, Boucek RJ, Boerth RJ, Breitweser JA, Thompson S, et al. Assessment of ventricular size and function in congenitally corrected transposition of the great arteries. Am J Cardiol 1983; 51: 244-251.

18. Petrie MC, Mc Murray JJ. It cannot be cardiac failure because the heart is not enlarged on chest X-ray. Eur J Heart Fail 2003; 5: $117-119$

19. Clark AL, Coats AJ. Unreliability of cardio-thoracic ratio as a marker of ventricular impairment: Comparison with radionuclide ventriculography and echocardiography. Postgrad Med J 2000; 76: 289-291.

20. Kammeraad JA, van Deurzen CH, Sreeram N, Bibk-Boelkens MT, Ottenkamp J, Helbing WA, et al. Predictors of sudden cardiac death after Mustard or Senning repair for transposition of the great arteries. J Am Coll Cardiol 2004; 44: 1095-1102.

21. Hauser M, Meierhofer CH, Schwaiger M, Vogt M, Kaemmerer H, Kuehn A. Myocardial blood flow in patients with transposition of the great arteries: Risk factor for dysfunction of the morphologic systemic right ventricle late after atrial repair. Circ J 2015; 79: 425431.
22. Trojnarska O, Gwizdata A, Katarzynski S, Katarzynska A, Sarnowska Z, Breborowicz P, et al. Evaluation of exercise capacity with cardiopulmonary exercise testing and BNP levels in adult patients with single- or systemic right ventricles. Arch Med Sci 2010; 30: $192-197$.

23. Bolger AP, Sharma R, Li W, Leenarts M, Kalra PR, Kemp M, et al. Neurohormonal activation and the chronic heart failure syndrome in adults with congenital heart disease. Circulation 2002; 106: 92-99.

24. Book WM, Hott BJ, McConnell M. B-type natriuretic peptide levels in adults with congenital heart disease and right ventricular failure. Am J Cardiol 2005; 95: 545-546.

25. Eindhoven JA, van den Bosch AE, Jansen PR, Boersma E, RoosHesselink JW. The usefulness of brain natriuretic peptide in complex congenital heart disease. J Am Coll Cardiol 2012; 60: 2140-2149.

26. Eindhoven JA, van den Bosch AE, Ruys TP, Opic P, Cuypers JA, McGhie JS, et al. N-terminal pro-B-type natriuretic peptide and its relationship with cardiac function in adults with congenital heart disease. J Am Coll Cardiol 2013; 62: 1203-1212.

27. Giannakoulas G, Dimopoulos K, Bolger AP, Tay EL, Inuzuka R, Bedard E, et al. Usefulness of natriuretic peptide levels to predict mortality in adults with congenital heart disease. Am J Cardiol 2010; 105: $869-873$.

28. Clerico A, Recchia FA, Passino C, Emdin M. Cardiac endocrine function is an essential component of the homeostatic regulation network: Physiological and clinical implications. Am J Physiol Heart Circ Physiol 2006; 290: H17-H29.

29. Masson S, Latini R, Anand IS, Vago T, Angelici L, Barlera S, et al. Direct comparison of B-type natriuretic peptide (BNP) and aminoterminal proBNP in a large population of patients with chronic and symptomatic heart failure: The Valsartan Heart Failure (Val-HeFT) data. Clin Chem 2006; 52: 1528-1538.

30. Daniels LB, Maisel AS. Natriuretic peptides. J Am Coll Cardiol 2007; 50: $2357-2368$.

31. Rubattu S, Sciarretta S, Valenti V, Stanzione R, Volpe M. Natriuretic peptides: An update on bioactivity, potential therapeutic use, and implication in cardiovascular diseases. Am J Hypertens 2008; 21: $733-741$.

32. Plymen CM, Hughes ML, Picaut N, Panoulas VF, MacDonald ST, Cullen $\mathrm{S}$, et al. The relationship of systemic right ventricular function to ECG parameters and NT-proBNP levels in adults with transposition of the great arteries late after Senning or Mustard surgery. Heart 2010; 96: $1569-1573$.

33. Kozelj M, Prokselj K, Berden P, Jan M, Osredkar J, Bunc M, et al. The syndrome of cardiac failure in adults with congenitally corrected transposition. Cardiol Young 2008; 18: 599-607.

34. Koch AM, Zink S, Singer H. B-type natriuretic peptide in patients with systemic right ventricle. Cardiology 2008; 110: 1-7.

35. Larsson DA, Meurling CJ, Holmqvist F, Waktare JE, Thilen UJ. The diagnostic and prognostic value of brain natriuretic peptides in adults with a systemic morphologically right ventricle or Fontan-type circulation. Int J Cardiol 2007; 114: 345-351.

36. Ohuchi H, Takasugi H, Ohashi H, Okada Y, Yamada O, Ono Y, et al. Stratification of pediatric heart failure on the basis of neurohormonal and cardiac autonomic nervous activities in patients with congenital heart disease. Circulation 2003; 108: 2368-2376.

37. Price JF, Thomas AK, Grenier M, Eidem BW, O'Brien Smith E, Denfield SW, et al. B-type natriuretic peptide predicts adverse cardiovascular events in pediatric outpatients with chronic left ventricular systolic dysfunction. Circulation 2006; 114: $1063-1069$.

38. Tan LH, Jefferies JL, Liang JF, Denfield SW, Dreyer WJ, Mott AR, et al. Concentrations of brain natriuretic peptide in the plasma predicts outcomes of treatment of children with decompensated heart failure admitted to the Intensive Care unit. Cardiol Young 2007; 17: $397-406$.

39. Sarkar B, Bull C, Yates R, Wright D, Cullen S, Gewillig M, et al. Comparison of long-term outcomes of atrial repair of simple transposition with implications for a late arterial switch strategy. Circulation 1999; 160: 176-181.

40. Reich O, Voriskova M, Ruth C, Krejcir M, Merek J, Skovranec J, et al. Long term ventricular performance after intra-atrial correction of transposition: Left ventricular filling is the major limitation. Heart 1997; 78: 376-381.

41. Redfield MM, Rodeheffer RJ, Jacobsen SJ, Mahoney DW, Bailey KR, Burnett JC. Plasma brain natriuretic peptide concentration: Impact of age and gender. J Am Coll Cardiol 2002; 40: 976-982.

42. Luchner A, Behrens G, Stritzke J, Markus M, Stark K, Peters A, et al. Long-term pattern of brain natriuretic peptide and $\mathrm{N}$-terminal pro brain natriuretic peptide and its determinants in the general population: Contribution of age, gender and cardiac and extra-cardiac factors. Eur J Heart Fail 2013; 15: 859-867. 